\title{
Analytical Approach for Modeling Axisymmetric Levee Underseepage
}

\author{
Christopher L. Meehan ${ }^{1}$; Sittinan Benjasupattananan ${ }^{2}$
}

\begin{abstract}
A variety of real-world levee underseepage problems can best be modeled using an axisymmetric analysis approach. In current practice, axisymmetric levee underseepage analyses are performed using numerical modeling approaches, such as the FEM. In contrast, levee underseepage analyses of planar cross sections are often analyzed using a blanket theory analytical approach, which is quicker and more convenient than numerical modeling. To address this problem, this paper provides a derivation of a series of closed-form blanket theory analytical equations that can be used to perform an axisymmetric levee underseepage analysis. This derivation begins from the governing equation of semiconfined fluid flow beneath a levee in a shallow semiconfined aquifer. The equations that result from this derivation can be used to calculate the total head in the pervious foundation layer and the seepage quantity that passes through the levee foundation over time. Different equations are presented for different seepage directions relative to the axis of rotation and different model boundary conditions. A typical example problem is used to compare results from the axisymmetric analytical equations that are derived with those from axisymmetric finite-element analyses. For this example problem, the analytical equations yield results that are equal to or more conservative than those from the finite-element analysis, where conservative results correspond to greater seepage under the levee and higher heads at the levee toe.
\end{abstract}

DOI: $10.1061 /(\mathrm{ASCE}) \mathrm{GT} .1943-5606.0000952$

Keywords: Analytical approach; Groundwater flow; Levees; Underseepage; Axisymmetric flow; Blanket theory.

Copyright: This paper is part of the Journal of Geotechnical and Geoenvironmental Engineering, Vol. 140, No. 4, April 2014, ISSN ISSN 1090-0241. The copyright for this work is held by the American Society of Civil Engineers. The original publication of this work can be obtained by following the DOI link above.

Reference: Meehan, C. L. and Benjasupattananan, S. (2014). "Analytical Approach for Modeling Axisymmetric Levee Underseepage." Journal of Geotechnical and Geoenvironmental Engineering, ASCE, 140(4), 04013037.1-04013037.12. (doi:10.1061/(ASCE)GT.1943-5606.0000952)

Note: The manuscript for this paper was submitted for review and possible publication on December 11, 2012; approved for publication on April 22, 2013; and published online in April of 2013.

\section{Introduction}

When protecting low-lying areas from flooding, it is common practice to encircle the at-risk region with a flood protection embankment, which is commonly referred to as a ring dike or ring levee (e.g., FEMA 2003; Trimbath 2006; Jonkman et al. 2008). In a similar fashion, approximately circular levee-type embankment containment systems are often constructed at the ground surface to create an area for fluid impoundment during the construction of storm water/wastewater retention ponds or drinking/irrigation water retention facilities (e.g., Wooding 1968; Weir 1987; Haman et al. 1991). Circular embankment fluid contain-

\footnotetext{
${ }^{1}$ Bentley Systems Incorporated Chair of Civil Engineering \& Associate Professor, University of Delaware, Dept. of Civil and Environmental Engineering, 301 DuPont Hall, Newark, DE 19716, U.S.A. E-mail: cmeehan@udel.edu (corresponding author)

${ }^{2}$ Graduate Student, University of Delaware, Dept. of Civil and Environmental Engineering, 301 DuPont Hall, Newark, DE 19716, U.S.A.) E-mail: sittinan@udel.edu
}

ment facilities are also often constructed to contain the highly fluidic spoils that result from marine dredging or the tailings that result from a variety of industrial or miningrelated processes (e.g., Bouwer 1982; Ormann et al. 2011; Brixel et al. 2012).

When constructing these facilities, it is of paramount importance to check the overall stability of the embankment to ensure that catastrophic failure does not occur [e.g., Foster et al. 2000; U.S. Army COE (USACE) 2000; Van et al. 2005]. It is also important to assess the quantity of seepage that will pass through and/or beneath the embankment over time, assuming steady-state seepage conditions corresponding to the maximum level of differential fluid head that is expected from one side of the embankment barrier to the other, which is a worst-case seepage scenario (Turnbull and Mansur 1961; USACE 2000, 2005). Proper determination of the steady-state seepage flow regime is also important for assessing the pore pressures and seepage gradients in the embankment and foun- 
dation soils to ensure that uplift, erosion, and piping are not a problem for the embankment that has been constructed (Van Zyl and Harr 1981; McCook 2007).

Through proper design, it is fairly easy to construct an embankment that is relatively impermeable in comparison with the foundation soils at a given site. In this situation, seepage through the foundation soils will control the overall seepage behavior of the containment system. For long straight levee stretches, planar cross-section analyses are typically performed to model the seepage that occurs through the levee foundation (e.g., USACE 2000). However, for the seepage beneath a circular levee system, an axisymmetric modeling approach provides a more accurate model of the seepage that is occurring (Strack 1989). Axisymmetric modeling of the seepage that occurs beneath a circular levee system can be performed using numerical modeling approaches, such as finite-element or finitedifference analyses (e.g., Tracy 1973; Inci 2008). However, an equivalent closed-form analytical approach for axisymmetric seepage modeling does not currently exist. This is unfortunate because many engineers in practice in the United States are currently using closed-form analytical approaches for seepage analysis of planar levee cross sections (e.g., USACE 2000) and are quite comfortable with this analysis framework. Closed-form analytical approaches also offer significant advantages over numerical modeling tools for probabilistic modeling because the coupling of numerical modeling tools with repetitivecalculation approaches such as Monte Carlo simulation can be somewhat computationally expensive (e.g., Pula and Bauer 2007).

This paper provides a derivation of a series of closedform blanket theory analytical equations that can be used to perform an axisymmetric levee underseepage analysis. This derivation begins from the governing equation of semiconfined fluid flow beneath a levee in a shallow semiconfined aquifer. The equations that result from this derivation can be used to calculate the total head in the pervious foundation layer and the seepage quantity that passes through the levee foundation over time. Different equations are presented for different seepage directions relative to the axis of rotation and different model boundary conditions. A typical example problem is used to compare results from the axisymmetric analytical equations that are derived with those from axisymmetric finite-element analyses.

\section{Semiconfined Groundwater Flow: Cartesian Coordinate System (Planar Seepage)}

Meehan and Benjasupattananan (2012) provide a detailed discussion for the rationale behind using a closed-form blanket theory analytical approach to model planar seepage behavior in the foundation soil beneath levees. This type of analytical approach for modeling levee underseepage has a long history of use by the USACE (USACE 1956a, b, 2000; Turnbull and Mansur 1961) and other private engineering firms in the United States. It is widely

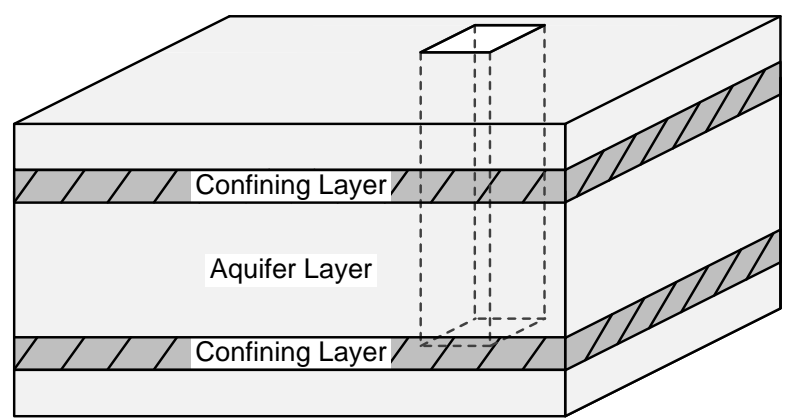

(a)

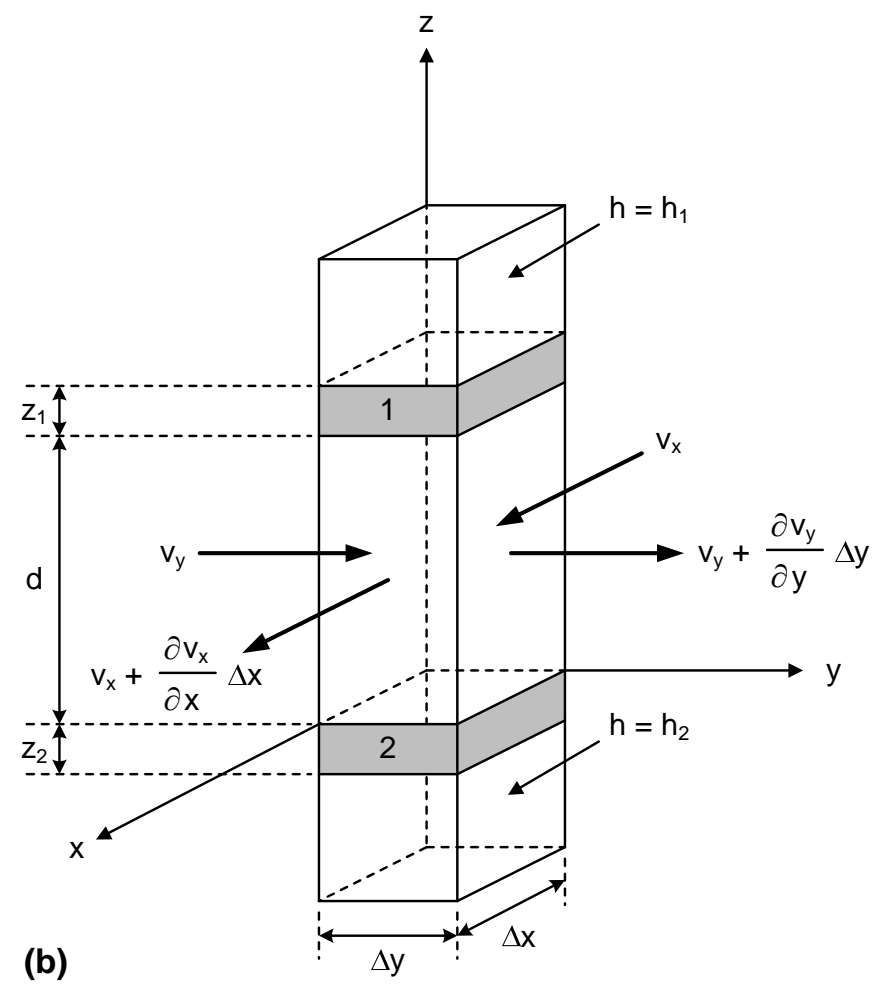

Fig. 1: Seepage in a semiconfined aquifer described by a Cartesian coordinate system: (a) subsurface seepage between soil confining layers; (b) continuity of seepage in an element of a confined aquifer (A. Verruijt, Theory of Groundwater Flow, published 1970 Macmillan reproduced with permission of Palgrave Macmillan).

accepted as a reasonable levee underseepage analysis tool, given the many uncertainties that are typically present when characterizing seepage model input parameters for levee analysis.

Typical blanket-theory analytical models assume that the flow of seepage beneath a levee can be characterized as shallow semiconfined groundwater flow in an aquifer. As used here, the term confined flow applies to the field case where leakage through subsurface soil-confining beds is negligibly small [Fig.1(a)]. If the leakage through the confining beds is significant enough that it cannot be neglected, the aquifer is considered to be semiconfined. The term shallow semiconfined flow is used whenever an aquifer is sufficiently shallow such that the resistance to flow in the vertical direction may be neglected (Strack 1989). 
When modeling seepage in a semiconfined aquifer using a Cartesian coordinate system characterized by $x, y$, $z$-coordinates [Fig. 1(b)], existing analytical models typically assume (1) that the permeable foundation layer is of constant thickness, $d$, and (2) that vertical velocities in the permeable foundation layer $\left(v_{z}\right)$ are small compared with the horizontal velocities $\left(v_{x}, v_{y}\right)$ (Meehan and Benjasupattananan 2012). The second assumption is important in the derivation because it indicates that the change in head along the thickness of the permeable layer $(\partial h / \partial z)$ will be relatively small compared with the change in head that occurs in the other spatial directions throughout the aquifer $(\partial h / \partial x, \partial h / \partial y)$. Following this assumption and utilizing Darcy's law and Laplace's equation, the governing differential equation of fluid flow throughout a shallow semiconfined aquifer in a Cartesian coordinate system can be derived to be (Meehan and Benjasupattananan 2012; Benjasupattananan 2013)

$$
k_{f} d\left(\frac{\partial^{2} h}{\partial x^{2}}+\frac{\partial^{2} h}{\partial y^{2}}\right)=\left(\frac{k_{1}\left(h-h_{1}\right)}{z_{1}}\right)+\left(\frac{k_{2}\left(h-h_{2}\right)}{z_{2}}\right)
$$

where $h=$ total head in the pervious foundation layer (the semiconfined aquifer); $k_{f}=$ horizontal hydraulic conductivity of the pervious foundation layer in units of length per time; $d=$ thickness of the pervious foundation layer; $k_{1}$ and $k_{2}=$ vertical hydraulic conductivities of the upper and lower confining layers, respectively; $h_{1}=$ total head in the layer above confining layer $1 ; h_{2}=$ total head in the layer below confining layer 2 ; and $z_{1}$ and $z_{2}=$ thicknesses of the upper and lower confining layers, respectively [Fig. 1(b)].

For modeling planar seepage beneath a uniform levee cross section that has an impermeable base layer, i.e., the type of seepage modeling that is typically performed using the USACE (2000) approach, Eq. (1) can be simplified to (Meehan and Benjasupattananan 2012)

$$
\frac{d^{2} h}{d x^{2}}=\frac{k_{1}\left(h-h_{1}\right)}{z_{1} k_{f} d}=\frac{h-h_{1}}{\lambda^{2}}
$$

where the leakage factor, $\lambda$, is defined as

$$
\lambda=\sqrt{\frac{z_{1} k_{f} d}{k_{1}}}
$$

Beneath the levee itself, where no leakage is occurring, Eq. (2) simplifies to $d^{2} h / d x^{2}=0$. Meehan and Benjasupattananan (2012) solve the associated differential equations for head beneath a planar (uniform) levee cross section for different model boundary condition combinations that are commonly encountered during levee underseepage modeling. The closed-form equations that result from this solution process can be used to define the head in the foundation layer on the riverside of a levee, beneath the levee itself, and on the landside of a levee. Meehan and Benjasupattananan (2012) also present equations for determining the quantity of seepage that passes beneath a levee over time for the different boundary condition combinations that are commonly utilized for levee underseepage modeling.

\section{Semiconfined Groundwater Flow: Cylindrical Coordinate System (Axisymmetric Seepage)}

As noted in the introduction, the current paper is focused on the development of closed-form analytical solutions that can be used for axisymmetric modeling of levee underseepage. The general assumptions that are made during the derivation that is summarized in this paper are the same as those that are made by Meehan and Benjasupattananan (2012) during the derivation of a similar set of planar flow equations, in particular, that the seepage in the levee foundation can be reasonably characterized as shallow semiconfined flow. These assumptions are also the same as those that are made in the derivation of the USACE (2000) levee underseepage analysis approach (Bennett 1946).

Following these assumptions, it is possible to transform the governing equation of seepage [Eq. (1)] for a Cartesian coordinate system $(x, y$, and $z$, as shown in Fig. 1) to a cylindrical polar coordinate system $(r, \theta$, and $z$, as shown in Fig. 2) that is more appropriate for use in axisymmetric analyses. The general mathematics that is involved in this sort of transformation is fairly straightforward and well accepted (e.g., Kreyszig 2010). For brevity, minor algebraic substitution and chain rule steps in this derivation are omitted here; interested readers are referred to Benjasupattananan (2013). The governing equation of shallow semiconfined flow that results from this process for the element shown in Fig. 2(b) is

$$
\begin{array}{r}
k_{f} d\left(\frac{\partial^{2} h}{\partial r^{2}}+\frac{1}{r} \frac{\partial h}{\partial r}+\frac{\partial^{2} h}{\partial \theta^{2}}\right)=\left(\frac{k_{1}\left(h-h_{1}\right)}{z_{1}}\right)+\ldots \\
\ldots\left(\frac{k_{2}\left(h-h_{2}\right)}{z_{2}}\right)
\end{array}
$$

In a similar fashion as for the Cartesian underseepage model described in the previous section, Eq. (4) assumes (1) that the permeable foundation layer is of constant thickness, $d$, and (2) that vertical velocities in the permeable foundation layer $\left(v_{z}\right)$ are small compared with the radial and angular velocities $\left(v_{r}, v_{\theta}\right)$.

For typical levee underseepage analyses, the base of the foundation layer is assumed to be relatively impermeable, which means that $k_{2}=0$. For axisymmetric flow conditions, there will be no variation in head in the $\theta$-direction, and thus the seepage in the foundation layer will only be occurring in the radial $(r)$ direction. Following these assumptions, the governing equation for axisymmetric shallow semiconfined seepage reduces to

$$
\frac{d^{2} h}{d r^{2}}+\frac{1}{r} \frac{d h}{d r}=\left(\frac{k_{1}\left(h-h_{1}\right)}{z_{1} k_{f} d}\right)=\frac{h-h_{1}}{\lambda^{2}}
$$


(a)
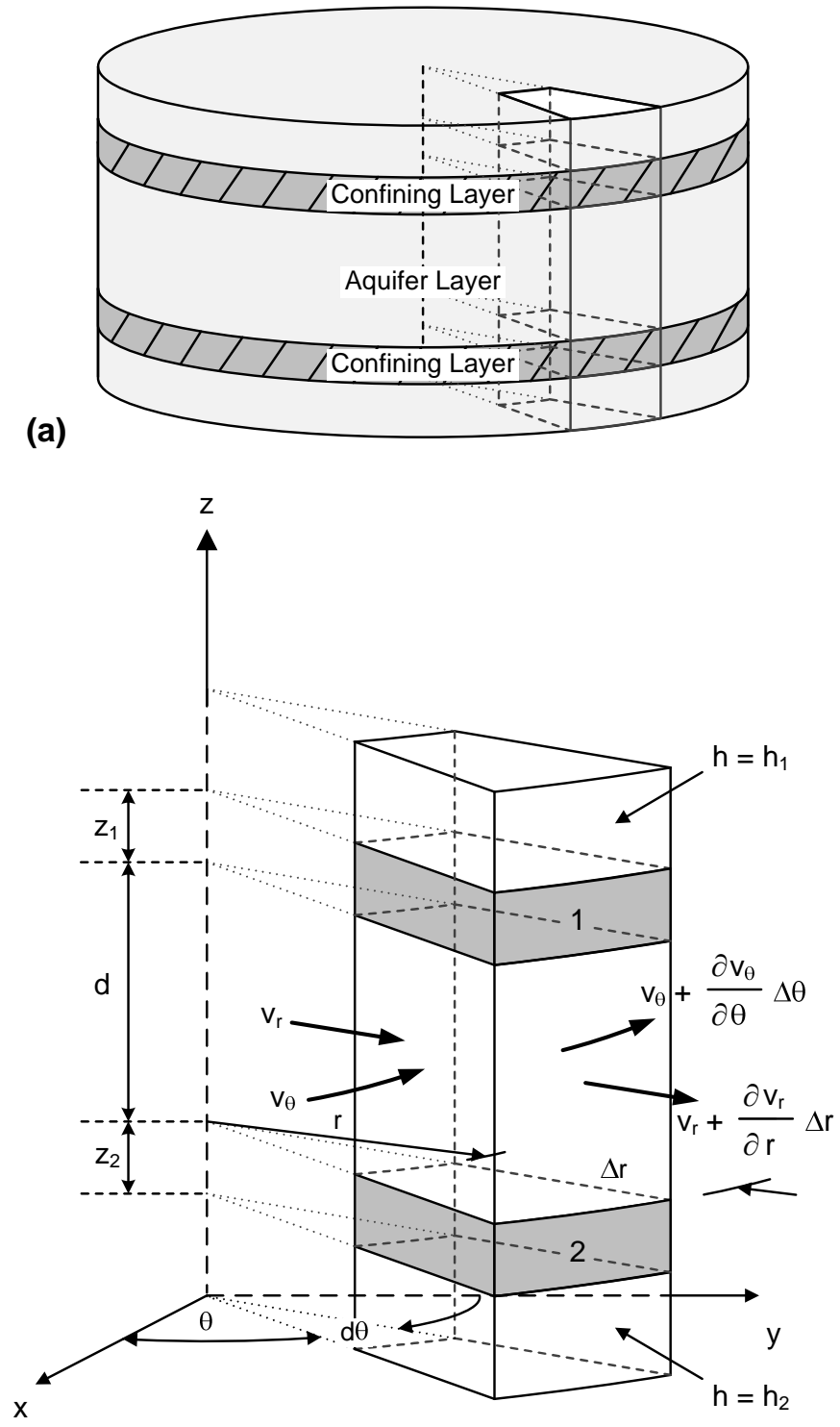

(b)

Fig. 2: Seepage in a semiconfined aquifer described by a cylindrical coordinate system: (a) subsurface seepage between soil confining layers; (b) continuity of seepage in an element of a confined aquifer.

The general similarity between Eqs. (1) and (4) and between Eqs. (2) and (5) can be readily observed. The additional term in Eq. (5) makes the solution to the differential equation that governs two-dimensional (2D) axisymmetric seepage beneath levees more complex than the solution for 2D planar seepage.

\section{Defining the Problem Geometry}

Fig. 3(a) shows a plan view schematic of an axisymmetric levee system. For axisymmetric levee systems that are being designed to protect an area from flooding, the radial seepage pattern that occurs is from the outside of the barrier to the inside, as shown in Fig. 3(b). For axisymmetric levee systems that are being used for fluid impoundment, the radial seepage pattern that occurs is from the inside of the barrier to the outside, as shown in Fig. 3(c). The two different levee configurations defined by these two directions of seepage relative to the axis of rotation will be referred to as the convex and concave levee configurations, respectively.
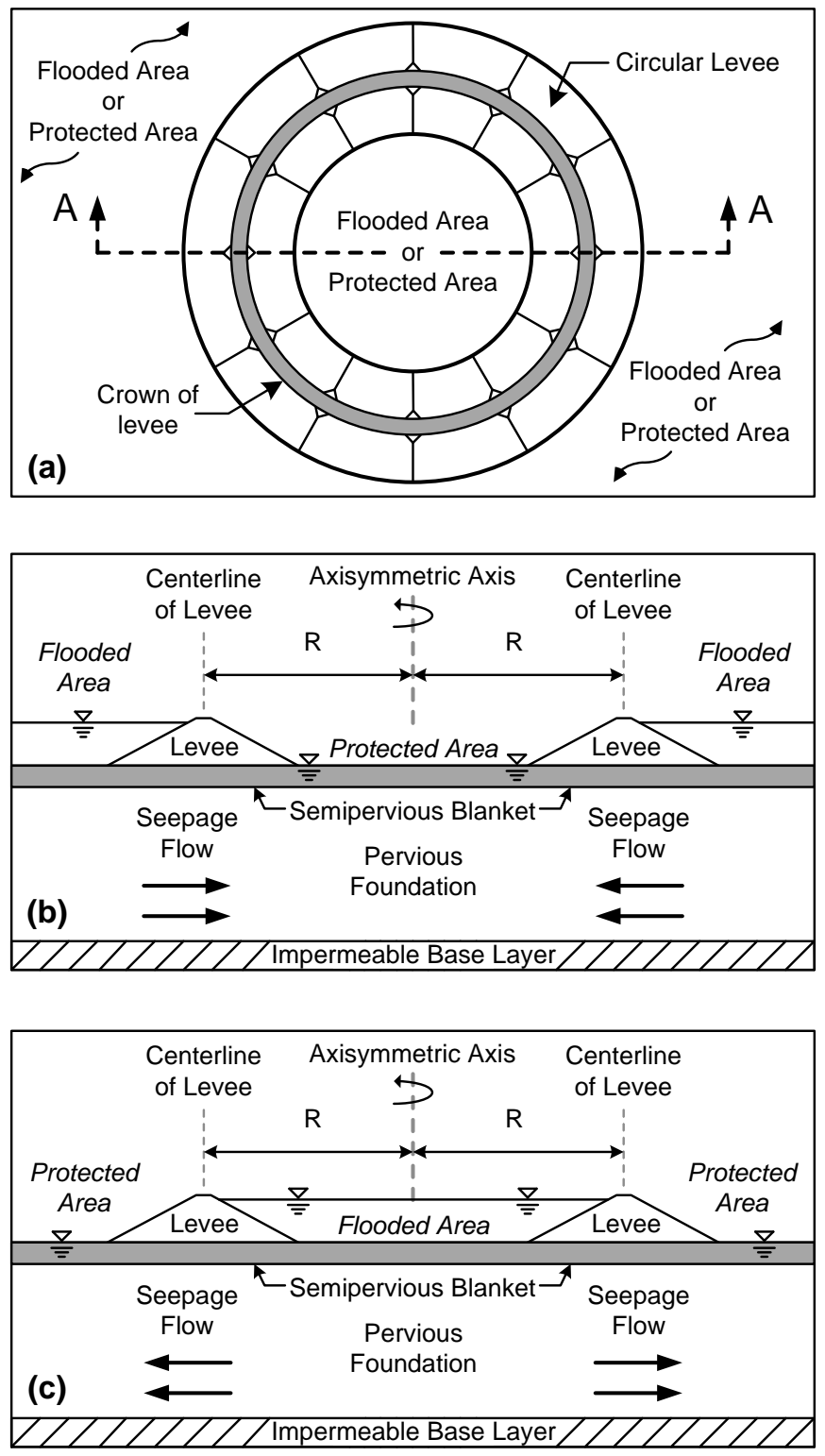

Fig. 3: Schematic view for axisymmetric levee underseepage (not to scale): (a) plan view of an axisymmetric levee system; (b) axisymmetric seepage from the outside of the levee to the inside (section A-A, convex levee configuration); (c) axisymmetric seepage from the inside of the levee to the outside (section A-A, concave levee configuration).

To solve Eq. (5), a reference coordinate system must be established; for the equations that are derived here, the radial distance $r$ is measured from the axis of rotation (Fig. 4). For the convex and concave seepage patterns shown in Fig. 3, it is necessary to divide the levee foun- 

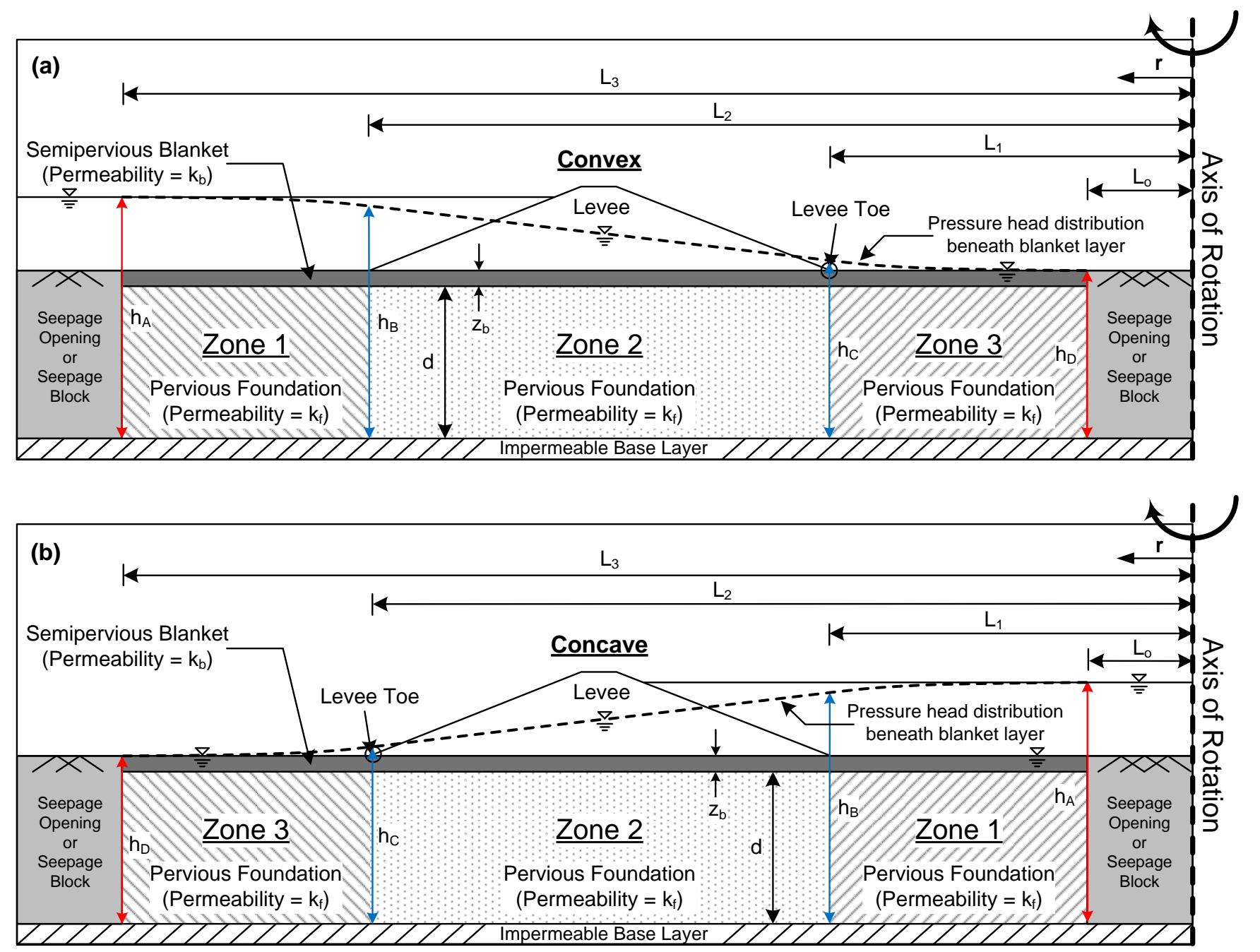

Fig. 4: Idealized cross section that is used for modeling axisymmetric levee underseepage: (a) convex levee configuration; (b) concave levee configuration.

dation into three distinct zones that each have a different pattern of leakage through the semipervious blanket: (1) Zone 1 on the side of the levee where water is being retained and where water is infiltrating through the semipervious blanket layer into the more pervious foundation layer; (2) Zone 2 beneath the levee where there is no leakage occurring into or out of the foundation layer through the overlying levee; and (3) Zone 3 on the dry side of the levee where water is flowing out of the pervious foundation layer through the semipervious blanket. Figs. 4(a and b) show these three foundation zones for convex and concave levee configurations, respectively.

Fig. 4 also shows the other input variables that are needed to determine the total fluid head in the pervious foundation layer $(h)$; as can be observed, radial dimensions of interest $\left(r, L_{0}, L_{1}, L_{2}\right.$, and $\left.L_{3}\right)$ are measured from the axis of rotation. The values of head in the pervious foundation at the outer boundaries of the analysis $\left(h_{A}, h_{D}\right)$ and the values of head in the pervious foundation at either toe of the levee $\left(h_{B}, h_{C}\right)$ can be measured from any consistent reference datum; for simplicity, the imperme- able base layer is used here. To be consistent with typical levee parlance, the upper semipermeable confining layer in the foundation is referred to as the semipervious blanket, which has a thickness of $z_{b}=z_{1}$ and a vertical hydraulic conductivity of $k_{b}=k_{1}$. Consequently, the corresponding values of $\lambda$ needed in the analyses may be calculated using the equation $\lambda=\sqrt{z_{b} k_{f} d / k_{b}}$.

For a given axisymmetric levee underseepage problem, it is also necessary to define the inner- and outer-radius boundary conditions that will govern the seepage behavior. As shown on the left and right side of the idealized cross section in Fig. 4, two boundary conditions are commonly used in levee underseepage analyses, a no-flow condition at the boundary, which is commonly referred to as a seepage block, or an applied head condition at the boundary, which is commonly referred to as a seepage opening (USACE 2000; Meehan and Benjasupattananan 2012). 


\section{Solving the Governing Differential Equations for Axisymmetric Levee Underseepage}

In Zone 1, leakage is occurring into the pervious foundation layer, and in Zone 3, leakage is occurring out of the pervious foundation layer. In both of these zones, the total fluid head in the pervious foundation layer can be determined by solving Eq. (5). In Zone 2, because no leakage is occurring into or out of the pervious foundation layer, the governing equation for the seepage reduces to

$$
\frac{d^{2} h}{d r^{2}}+\frac{1}{r} \frac{d h}{d r}=0
$$

This equation is a second-order ordinary differential equation, and its solution has the following functional form:

$$
h=C_{1} \ln r+C_{2}
$$

where $C_{1}$ and $C_{2}=$ unknown constants that are determined when the specific boundary conditions are applied.

In Zones 1 and 3, where leakage is occurring, the governing differential equation is a second-order ordinary differential equation with a nonconstant coefficient. In this case, the general solution cannot be determined using a simple mathematical expression, and a power series expansion approach can be utilized to solve the equation. For this particular approach, variable substitution allows the functional form of the governing equation [Eq. (5)] to be transformed to a functional form that can be solved using modified Bessel functions (e.g., Watson 1922; Abramowitz and Stegun 1964)

$$
\frac{d^{2} S}{d X^{2}}+\frac{1}{X} \frac{d S}{d X}=S
$$

where $S=$ drawdown $=h_{1}-h$; and $X=r / \lambda$.

Assuming that $h_{1}$ is a constant, which is typical for levee applications, and using a modified Bessel function approach, the solution to Eq. (8) has the following functional form:

$$
S=C_{3} I_{0}(X)+C_{4} K_{0}(X)
$$

where $C_{3}$ and $C_{4}=$ unknown constants that are determined when the specific boundary conditions are applied; and $I_{0}$ and $K_{0}=$ zero-order modified Bessel functions of $X$ of the first and second kind, respectively. Using substitution, Eq. (9) can also be written as

$$
h=h_{1}-C_{3} I_{0}(r / \lambda)-C_{4} K_{0}(r / \lambda)
$$

Boundary conditions for Zones 1-3 can then be applied, which allows the preceding differential equation solutions [Eqs. (7) and (10)] to be solved separately for each zone to yield an equation for the head beneath the blanket layer $\left(h_{r}\right)$ as a function of radial distance $(r)$ from the axis of rotation, as shown in Fig. 4. As noted previously, two analysis boundary conditions are common in levee underseepage analyses, a no-flow condition at the boundary (e.g., $d h / d r=0)$, which is commonly referred to as a seepage block or an applied head condition at the boundary (e.g., $h=$ known head value), which is commonly referred to as a seepage opening (Fig. 4). These two boundary conditions are the same as those that are used for analysis of planar cross sections in the USACE levee underseepage analysis approach (i.e., Cases 7b and 7c; USACE 2000).

Tables 1 and 2 provide the resulting differential equation solutions for Zones 1-3, for convex and concave levee configurations, respectively. These solutions allow for the calculation of the total fluid head in the pervious foundation as a function of distance from the axis of rotation. As shown in Tables 1 and 2, the equations that should be used in Zones 1 and 3 are different, depending upon whether a seepage block or seepage opening boundary condition is present on the outermost boundary of each zone. For interested readers, Benjasupattananan (2013) provides a detailed step-by-step derivation of the equations shown in Tables 1 and 2; for brevity, the minor algebraic steps that are utilized during the solution process are omitted here.

In Tables 1 and 2, $I_{0}$ and $K_{0}$ are zero-order modified Bessel functions of the first and second kind, respectively, and $I_{1}$ and $K_{1}$ are first-order modified Bessel functions of the first and second kind, respectively. These modified Bessel functions are power expansions, and they can be easily utilized with built-in functions that are readily available in typical engineering software such as Microsoft Excel or MATLAB 7.12.

For a specific levee underseepage problem, the position of the head line in any one of the three foundation zones is affected by the seepage behavior in the other two foundation zones. To include this effect in the analytical solution, seepage continuity needs to be applied at the interface between each zone. Specifically, the seepage through Zone 1 has to be equal to the seepage through Zone 2, and the seepage through Zone 2 has to be equal to the seepage through Zone 3. By applying seepage continuity in this fashion, intermediate values of head at the interior zone boundaries $\left(h_{B}\right.$ and $\left.h_{C}\right)$ can be determined; in this approach, the two equations of continuity are used to solve for the values of the two unknowns (Benjasupattananan 2013). The equations for $h_{B}$ and $h_{C}$ that result from this process are

$$
\begin{gathered}
h_{B}=\frac{(A+1) B h_{A}+A h_{D}}{A+(A+1) B} \\
h_{C}=(B+1) h_{B}-B h_{A}
\end{gathered}
$$

where the coefficients $A$ and $B$ are determined using the equations provided in Tables 3 and 4 for convex and concave levee geometries, respectively. As shown in Tables 3 and 4 , there are four possible combinations of boundary conditions that may be selected during this process, each 


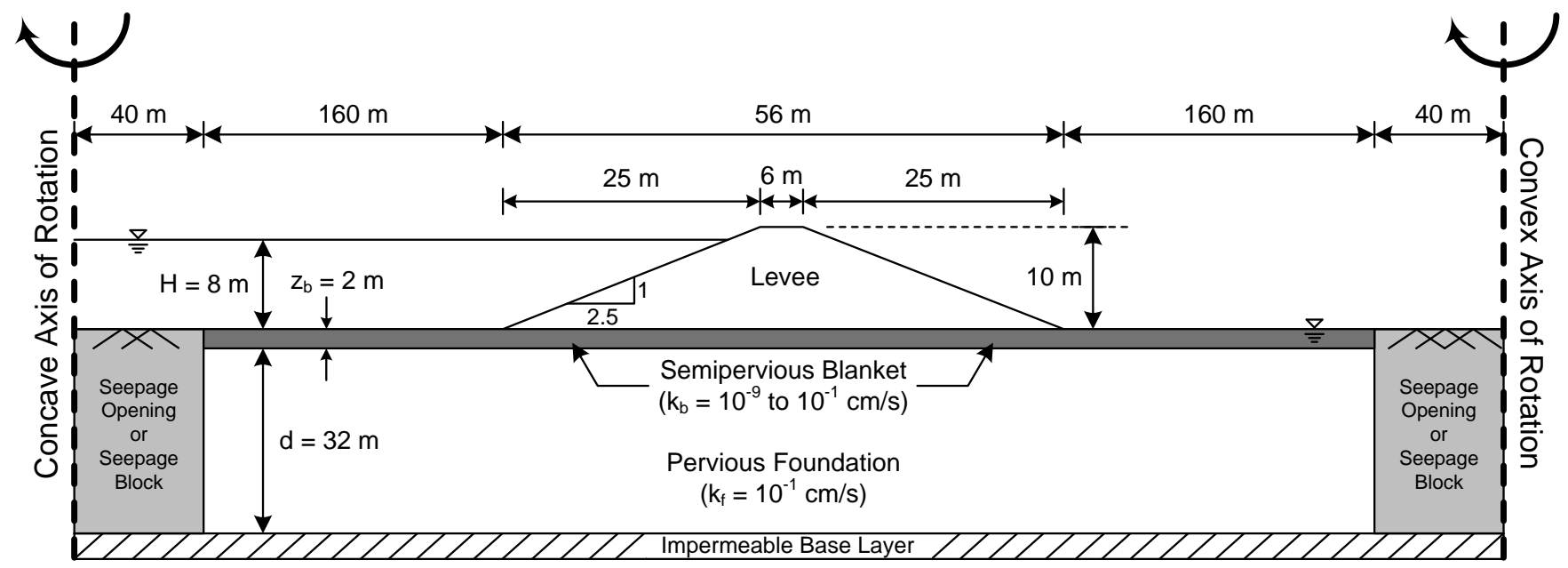

Fig. 5: Simple levee underseepage case (not to scale).

of which yield different coefficients for use in Eqs. (11) and (12): (1) Zone 1 seepage block and Zone 3 seepage block; (2) Zone 1 seepage opening and Zone 3 seepage block; (3) Zone 1 seepage block and Zone 3 seepage opening; and (4) Zone 1 seepage opening and Zone 3 seepage opening.

For design purposes, the total head beneath the semipervious blanket layer at the landside levee toe is equal to $h_{C}$. For the datum that is used in the derivation, the net pressure head across the semipervious blanket layer at the landside levee toe $\left(h_{t o e}\right)$ can be calculated using the equation

$$
h_{\text {toe }}=h_{C}-h_{D}
$$

For a convex levee configuration, the total quantity of seepage $(Q)$ passing through the foundation layer for a unit arc levee $\left(L^{3} / T /\right.$ radian $)$ can be calculated using the equation

$$
Q / \text { radian }=k_{f} d\left(\frac{h_{B}-h_{C}}{\ln \left(L_{2} / L_{1}\right)}\right)
$$

In a similar fashion, for a concave levee configuration, the total quantity of seepage $(Q)$ passing through the foundation layer for a unit arc levee can be calculated using the equation

$$
Q / \text { radian }=k_{f} d\left(\frac{h_{C}-h_{B}}{\ln \left(L_{1} / L_{2}\right)}\right)
$$

\section{Simple Levee Underseepage Case}

To illustrate how the analytical solutions that are described in the previous sections work, it is instructive to examine the behavior of a simple axisymmetric levee system (Fig. 5) that is being used to either (1) protect an area from flooding or (2) impound water. As shown, a homogeneous, impermeable axisymmetric levee, $10 \mathrm{~m}$ high, with a 6-m-wide crest and 2.5:1 side slopes, is constructed on top of a two-layer foundation. The foundation consists of a long, finite-length semipervious blanket that is $2 \mathrm{~m}$ thick, which overlies a more pervious foundation layer that has a thickness of $32 \mathrm{~m}$. At the design flood level, the levee is intended to either hold back $8 \mathrm{~m}$ of water (convex levee configuration) or impound $8 \mathrm{~m}$ of water (concave levee configuration). For this example, a relatively high hydraulic conductivity of $10^{-1} \mathrm{~cm} / \mathrm{s}$ was selected for the foundation soil $\left(k_{f}=10^{-1} \mathrm{~cm} / \mathrm{s}\right)$, and the hydraulic conductivity of the blanket layer soil $\left(k_{b}\right)$ was varied parametrically from $10^{-9}$ to $10^{-1} \mathrm{~cm} / \mathrm{s}$ (a range of low to high permeabilities). Also explored in the analysis is the effect of the lateral boundary conditions on the model results. As noted previously, four boundary condition combinations are possible, and the analyses that were performed consequently examined each combination.

\subsection{Axisymmetric Levee Underseepage Analysis Using the Analytical Method}

This section utilizes the analytical equations that are derived in this paper to determine the levee underseepage behavior for the example problem that is shown in Fig. 5. Fig. 6 shows two critical design parameters of interest that result from the axisymmetric analytical analyses that were performed for this example problem: the net pressure head across the semipervious blanket layer at the landside levee toe $\left(h_{t o e}\right)$ and the normalized quantity of seepage $(Q)$ that passes through the levee foundation per unit time. Results are presented for a convex levee configuration [Fig. 6(a)] and a concave levee configuration [Fig. 6(b)], and for varying blanket permeabilities and boundary condition combinations. Note that the different values of $\lambda$ that are shown correspond to the different values of $k_{b}$ that were analyzed. Also shown on these figures are the results from the axisymmetric finite-element analyses that are described in the following section for comparison purposes.

As shown in Fig. 6, as the hydraulic conductivity of the semipervious blanket changes, as shown by the changing 

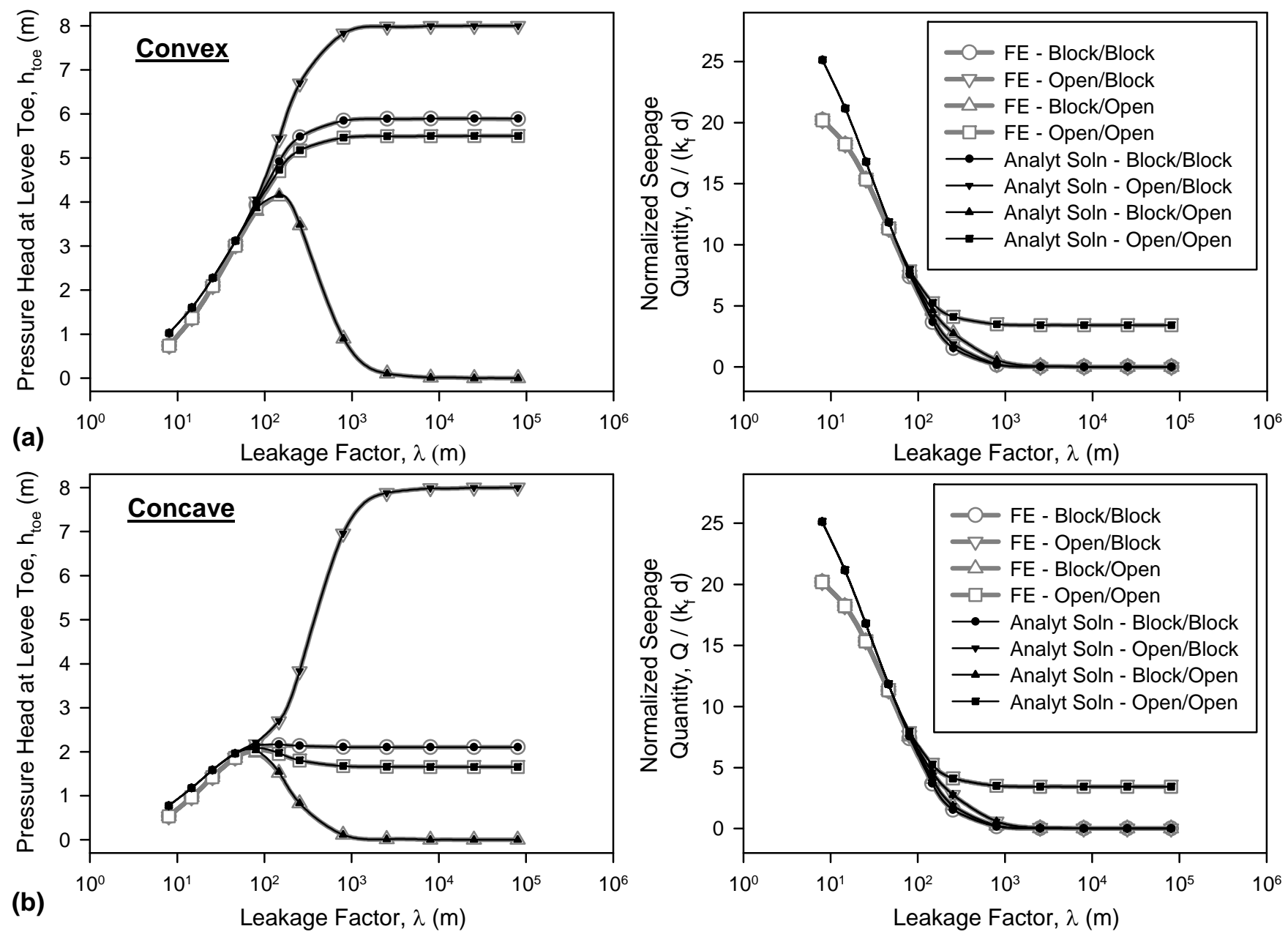

Fig. 6: Comparison of results from the analytical equations that are presented in this paper and finite-element analysis for seepage block and seepage opening boundary conditions; results are presented for the net pressure head beneath the blanket layer at the landside levee toe and the normalized quantity of seepage that passes through the levee foundation per unit time for varying blanket permeabilities: (a) convex levee configuration; (b) concave levee configuration.

values of $\lambda$ along the $x$-axis of the figure, the net pressure head beneath the blanket layer at the landside levee toe and the normalized quantity of seepage that passes through the levee foundation per unit time changes. This is not a surprising observation because the blanket hydraulic conductivity controls the rate at which leakage occurs into and out of the pervious foundation layer, all other input parameters being equal.

Also as shown in Fig. 6, for semipervious blanket layers that are relatively permeable (the lower values of $\lambda$ that are shown), the boundary conditions that are selected tend to not have a significant effect on the results because a large portion of the buildup and dissipation of excess hydraulic head is occurring due to vertical flow near the levee toes rather than horizontal flow to and from the model boundaries. However, for semipervious blanket layers that are relatively impermeable, the boundary conditions that are selected have a very significant effect on the results. As shown in Fig. 6, if one focuses on the net pressure head at the landside levee toe $\left(h_{t o e}\right)$ and the seepage quantity through the levee foundation $(Q)$ as the design parameters of interest for this example problem, then the boundary conditions begin to have an effect at blanket permeabilities less than $10^{-3} \mathrm{~cm} / \mathrm{s}$ or so (at $\lambda$ values greater than 80). At blanket permeabilities less than $6 \times 10^{-6} \mathrm{~cm} / \mathrm{s}$ or so (at $\lambda$ values greater than 1,000 ), the curves for net pressure head at the levee toe and quantity of seepage in the levee foundation per unit time begin to level off, indicating that the blanket layer is relatively impermeable at this point. This behavior is generally consistent with observations that have been made by Meehan and Benjasupattananan (2012).

\subsection{Axisymmetric Levee Underseepage Analysis Using the FEM}

To validate the closed-form analytical solutions that are presented in this paper, a series of axisymmetric steadystate levee underseepage analyses was performed using the FEM. For simplicity, these simulations were conducted in parallel for the simple axisymmetric levee case that is shown in Fig. 5 for both the convex and concave pat- 

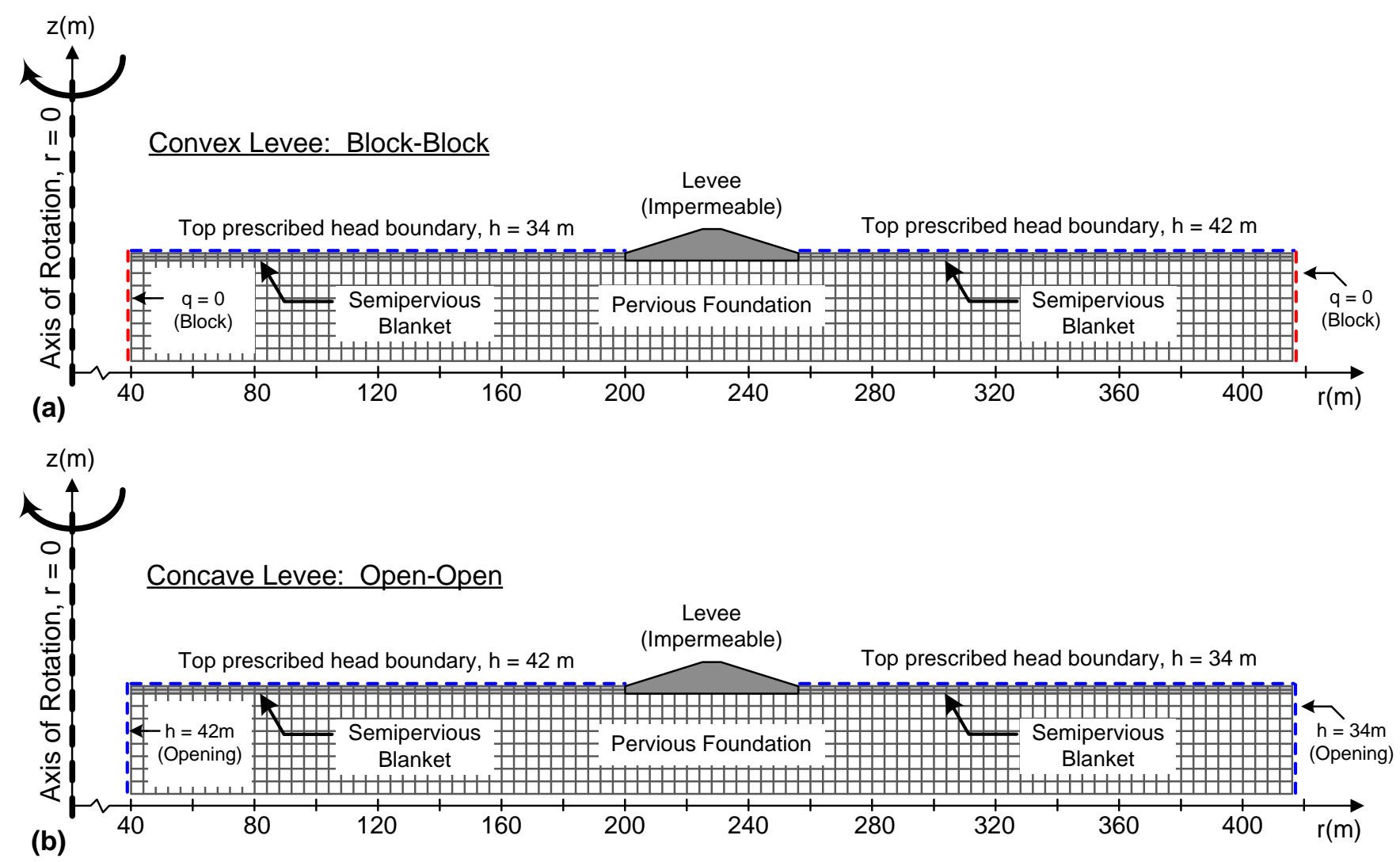

Fig. 7: Axisymmetric levee underseepage analysis using the FEM: (a) analysis mesh and boundary condition setup for a convex levee with seepage block-block boundary conditions; (b) analysis mesh and boundary condition setup for a concave levee with seepage open-open boundary conditions (levee shown for schematic purposes only, not included in the finite-element seepage model).

terns of seepage that were examined using the analytical equations. For purposes of analysis, the commercial finiteelement code SEEP2D (Aquaveo 2009) was utilized.

Fig. 7(a) shows a typical analysis mesh and boundary condition setup for the example problem that was simulated for a convex levee geometry and for seepage block boundary conditions on both sides of the problem (blockblock). Fig. 7(b) shows a typical analysis mesh and boundary condition setup for a concave levee geometry and for seepage opening boundary conditions on both sides of the problem (open-open). As shown in both of these figures, quadrilateral four-node elements were utilized in the finiteelement analyses, with different material properties being assigned for the semipervious blanket and pervious foundation layer, respectively.

As shown in Fig. 7, for all of the simulations that were performed, a constant-head boundary condition was utilized for the seepage infiltration and exfiltration areas along the upper boundary of the mesh, with different values of head being applied for the elements on either side of the levee. The difference between these two head values drives the direction of flow relative to the axis of rotation, which determines if a convex or a concave seepage problem is being simulated. To be consistent with the analytical approach, the inside mesh boundary was set to be $40 \mathrm{~m}$ away from the axis of rotation in the finite-element model (Fig. 7). The levee itself and the portion of the blanket layer immediately beneath it were considered impermeable in the analyses (no flow), and are consequently not part of the analysis mesh; this is consistent with the assumptions that were made during the analytical equation derivation. Along the lower boundary of the mesh (the impermeable base layer), a no-flow boundary condition was applied. At the left- and right-most boundaries, the boundary condition was set to be either a no-flow boundary or a constant-head boundary, depending upon the type of problem that was being modeled. To be consistent with the analytical problems that were simulated, four left- and right-side boundary condition combinations were examined using finite-element analysis.

Fig. 6 shows the $h_{\text {toe }}$ and normalized $Q$ values that result from the finite-element analyses that were performed. In this figure, finite-element analysis results are presented alongside the corresponding analytical model results for a convex levee configuration [Fig. 6(a)] and a concave levee configuration [Fig.6(b)], for varying blanket permeabilities and boundary condition combinations. As shown in Fig. 6, the results between the analytical equations and the FEM are in exact agreement with each other at values of $\lambda$ greater than 80 (at blanket hydraulic conductivities less than $10^{-3} \mathrm{~cm} / \mathrm{s}$ ). At values of $\lambda$ less than 80 , the results predicted by the two analysis methods are still fairly 


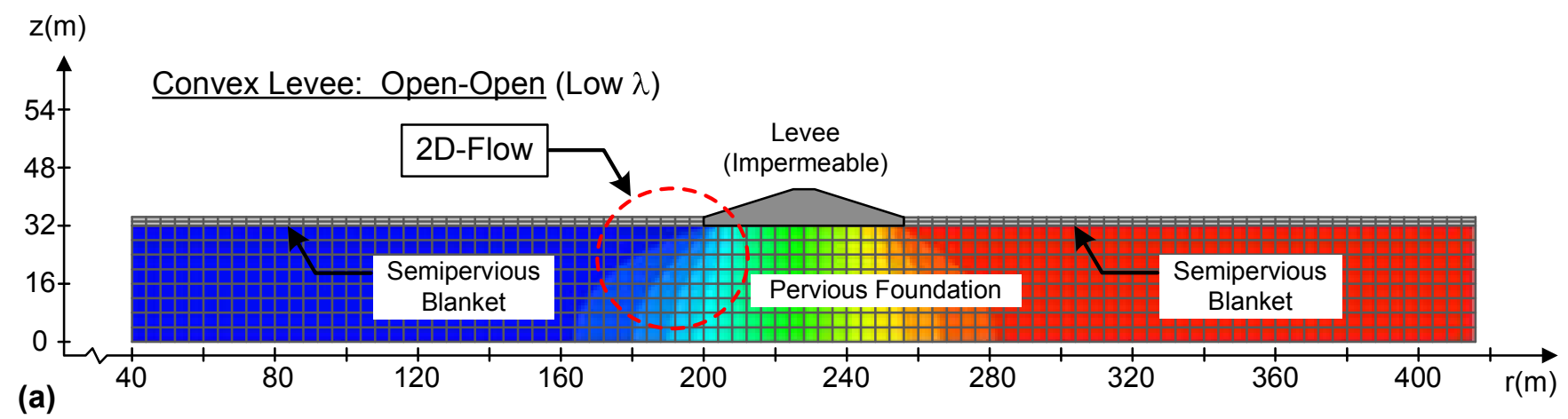

(a)

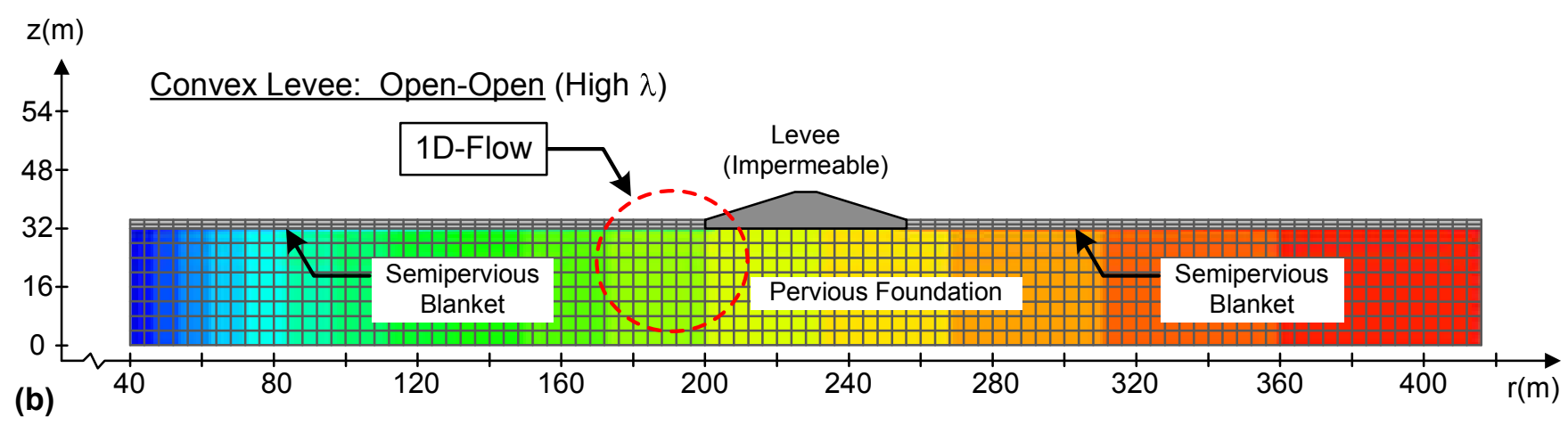

Fig. 8: Axisymmetric levee underseepage finite-element results: (a) contours of head in the foundation layer for a high permeability (low $\lambda$ ) blanket (convex levee, open-open boundary conditions); (b) contours of head in the foundation layer for a low permeability (high $\lambda$ ) blanket (convex levee, open-open boundary conditions).

close together; however, the analytical model results tend to diverge from those predicted by the FEM, with a larger difference being observed at smaller values of $\lambda$ (higher blanket hydraulic conductivities).

The difference in results between these two analysis approaches that was observed at lower values of $\lambda$ is caused by an assumption that is made in the derivation of the axisymmetric blanket theory equations: that vertical velocities in the permeable foundation layer $\left(v_{z}\right)$ are small compared with the radial velocities $\left(v_{r}\right)$. This assumption has an important effect in the derivation, and it is only reasonable for cases where the change in head along the thickness of the permeable layer $(\partial h / \partial z)$ is relatively small compared with the change in head that occurs in the radial direction $(\partial h / \partial r)$. For highly permeable blankets that do not significantly restrict flow into or out of the pervious foundation layer (i.e., low $\lambda$ blankets), one-dimensional flow behavior is not a realistic assumption [Fig. 8(a)]. However, for more semipermeable blankets that do exhibit some flow restriction (i.e., high $\lambda$ blankets), the assumption of onedimensional flow is quite reasonable [Fig. 8(b)].

In any case, the analytical equations presented in this paper yield results that are equal to or more conservative than those from the finite-element analyses. The results shown in Fig. 6 support this observation; if any divergence in model results does occur, the analytical results yield higher values of $h_{\text {toe }}$ and $Q$ for both the convex and concave levee configurations over all of the values of $\lambda$ that were analyzed (i.e., $10^{1} \leq \lambda \leq 10^{5}$ ). This makes the blanket theory assumption that was used in the derivation of the axisymmetric levee underseepage equations a reasonable one for most axisymmetric levee problems, an observation which is consistent with the widely accepted use of blanket theory analysis for planar levee sections in the United States (e.g., USACE 2000).

The general usefulness of the equations that are presented herein is only limited by the assumptions that are used in their derivation, in particular, the need for constant layer thicknesses and simplified geometry. In situations where the foundation layer thickness and/or blanket thickness are not fairly consistent, the use of the proposed equations will not produce results that are as reliable as finite-element analyses that take into account the nature of the varying geology. Simplified blanket-theory equations of the type that are derived herein also do not work well for certain multilayer geologies that cannot be reasonably represented using a two-layer system (e.g., Gabr et al. 1996); finite-element analyses or the three-layer modeling approach suggested by Gabr et al. (1996) are recommended in this situation.

\section{Summary and Conclusions}

This paper provides a derivation of a series of closedform blanket theory analytical equations that can be used to perform an axisymmetric levee underseepage analysis. This derivation assumes that a given axisymmetric levee problem can be generalized using a simplified two-layer geometry, where a lower permeability blanket layer overlies a more pervious foundation layer through which seepage 
occurs. For more complex geologies, USACE (2000) provides equations for transforming multilayer systems into an equivalent two-layer system that can be used in conjunction with the equations that are presented herein. Within the defined two-layer system, the flow in the pervious foundation layer is assumed to be analogous to the seepage that occurs in a shallow semiconfined aquifer, where the flow is predominantly horizontal in the pervious foundation layer, with some fluid infiltration and exfiltration occurring due to the effect of leakage through the semipervious blanket.

The equations that result from the derivation can be used to calculate the total head in the pervious foundation layer and the seepage quantity that passes through the levee foundation over time. For demonstration purposes, a simple axisymmetric levee example problem is analyzed using these equations. For the given levee cross section, convex and concave patterns of seepage are analyzed for varying blanket permeabilities for each of the four possible boundary condition combinations that can occur. Sideby-side axisymmetric finite-element analyses are also performed for each of the different cases that were assessed using the analytical equations. From these analyses, the following observations can be made:

1. For the given example problem, the analytical equations in this paper yield results that are equal to or more conservative than those from the finite-element analysis, where conservative results correspond to greater seepage under the levee and higher heads at the levee toe. This observation supports the use of a blanket theory approach for axisymmetric analysis of levee underseepage, a conclusion that is consistent with the use of blanket theory analytical methods for underseepage analyses of planar cross sections (USACE 2000).

2. For the example problem, the results predicted by the analytical method are the same as those predicted by the FEM at values of $\lambda$ greater than 80 . At values of $\lambda$ less than 80 , some divergence between the results begins to occur due to the assumption that only horizontal flow can occur in the pervious foundation layer.

3. For the example problem, the effect of the assumed boundary conditions becomes apparent at values of $\lambda$ greater than 80 . At $\lambda$ values greater than 1,000 or so, the curves for net pressure head at the levee toe and quantity of seepage in the levee foundation per unit time begin to level off, indicating that the blanket layer is relatively impermeable at this point.

The analytical equations that are presented in this paper provide engineers with a practical tool for performing axisymmetric levee underseepage analyses. They can be easily coded into a spreadsheet or other type of computer program for day-to-day analysis purposes. Given their relative computational efficiency, they are particularly well-suited for reliability analyses, especially for problems that require computationally expensive Monte Carlo simulations. They also have the potential for use in evaluating the three-dimensional effects of river bends on levee underseepage, as described by Benjasupattananan (2013).

\section{Acknowledgments}

The first author acknowledges the support of the Fulbright Center in Finland and the 2012-2013 Fulbright-Tampere University of Technology Scholar Award, which provided support for work on this manuscript. The second author gratefully acknowledges the Royal Thai Government for providing financial support for his graduate education. The authors also acknowledge the suggestions and assistance of Prof. Holly Michael of the University of Delaware.

\section{Notation}

The following symbols are used in this paper:

$A=$ coefficient whose value is determined using the analytical solution process;

$B=$ coefficient whose value is determined using the analytical solution process;

$C_{1}=$ unknown constant that is solved for when the analysis boundary conditions are known;

$C_{2}=$ unknown constant that is solved for when the analysis boundary conditions are known;

$C_{3}=$ unknown constant that is solved for when the analysis boundary conditions are known;

$C_{4}=$ unknown constant that is solved for when the analysis boundary conditions are known;

$d=$ thickness of the pervious foundation layer (the semiconfined aquifer);

$H=$ net head on levee;

$h=$ total head in the pervious foundation layer (the semiconfined aquifer);

$h_{A}=$ total head in the pervious foundation at the outermost boundary of Zone 1;

$h_{B}=$ total head in the pervious foundation at the inner boundary of Zone 1;

$h_{C}=$ total head in the pervious foundation at the inner boundary of Zone 3;

$h_{D}=$ total head in the pervious foundation at the outermost boundary of Zone 3;

$h_{r}=$ total head in the pervious foundation layer at a distance $r$ from the axis of rotation;

$h_{t o e}=$ net pressure head across the semipervious blanket layer at the landside levee toe;

$h_{1}=$ total head in the layer above confining layer 1 ;

$h_{2}=$ total head in the layer below confining layer 2 ;

$I_{0}=$ zero-order modified Bessel function of the first kind;

$I_{1}=$ first-order modified Bessel function of the first kind;

$K_{0}=$ zero-order modified Bessel function of the second kind;

$K_{1}=$ first-order modified Bessel function of the second kind;

$k_{b}=$ vertical hydraulic conductivity of the semipervious blanket;

$k_{f}=$ horizontal hydraulic conductivity of the pervious foundation layer; 


$$
\begin{aligned}
k_{1}= & \text { vertical hydraulic conductivity of } \\
& \text { semipermeable layer } 1 ; \\
k_{2}= & \text { vertical hydraulic conductivity of } \\
& \text { semipermeable layer } 2 ; \\
L_{0}= & \text { distance from the axis of rotation to the } \\
& \text { nearest edge of the semipervious blanket; } \\
L_{1}= & \text { distance from the axis of rotation to the } \\
& \text { nearest levee toe; } \\
L_{2}= & \text { distance from the axis of rotation to the } \\
& \text { farthest levee toe; } \\
L_{3}= & \text { distance from the axis of rotation to the } \\
& \text { farthest edge of the semipervious blanket; } \\
Q= & \text { quantity of seepage passing through the levee } \\
& \text { foundation per unit time; } \\
r= & \text { cylindrical polar coordinate direction; } \\
S= & \text { drawdown }=h_{1}-h ; \\
v_{r}= & \text { specific discharge (Darcy velocity) in the } \\
& r \text {-direction; } \\
v_{x}= & \text { specific discharge (Darcy velocity) in the } \\
& x \text {-direction; } \\
v_{y}= & \text { specific discharge (Darcy velocity) in the } \\
& y \text {-direction; } \\
v_{z}= & \text { specific discharge (Darcy velocity) in the } \\
& z \text {-direction; } \\
v_{\theta}= & \text { specific discharge (Darcy velocity) in the } \\
& \theta \text {-direction; } \\
X= & \text { variable used in the modified Bessel function } \\
& \text { substitution }=r / \lambda ; \\
x= & \text { Cartesian coordinate direction; } \\
y= & \text { Cartesian coordinate direction; } \\
z= & \text { Cartesian coordinate direction and cylindrical } \\
& \text { polar coordinate direction; } \\
z_{b}= & \text { thickness of the semipervious blanket (the } \\
& \text { levee foundation top stratum) } \\
z_{1}= & \text { thickness of semipermeable layer } 1 ; \\
z_{2}= & \text { thickness of semipermeable layer } 2 ; \\
\theta= & \text { cylindrical polar coordinate direction; and } \\
\lambda= & \text { leakage factor. } \\
&
\end{aligned}
$$

\section{References}

Abramowitz, M., and Stegun, I. A. (1964). Handbook of mathematical functions with formulas, graphs, and mathematical tables, U.S. GPO, Washington, DC.

Aquaveo. (2009). SEEP2D primer, groundwater modeling system, GMS, Provo, UT.

Benjasupattananan, S. (2013). "Deterministic and probabilistic approaches for modeling levee underseepage." Ph.D. dissertation, Univ. of Delaware, Newark, DE.

Bennett, P. T. (1946). "The effect of blankets on seepage through pervious foundations." Trans. Am. Soc. Civ. Eng., $11,215-252$.

Bouwer, H. (1982). "Design considerations for earth linings for seepage contol." Ground Water, 20(5), 531-537.

Brixel, B., Caldwell, J. A., and Wels, C. (2012). "Groundwater issues in the design, operation, and closure of tailings, waste rock, and heap leach facilities." Proc., Tailings and Mine Waste 2012, Colorado State Univ., Fort Collins, CO 73-84.

FEMA. (2003). Guidelines and specifications for flood hazard mapping partners, Appendix H: Guidance for mapping of areas protected by levee systems, Washington, DC.

Foster, M., Fell, R., and Spannagle, M. (2000). "The statistics of embankment dam failures and accidents." Can. Geotech. J., 37(5), 1000-1024.

Gabr, M. A., Wolff, T. F., Brizendine, A. L., and Taylor, H. M. (1996). "Underseepage analysis of levees on two-layer and three-layer foundation." Comput. Geotech., 18(2), 85-107.

Haman, D.Z., Clark, G. A., and Pitts, D. J. (1991). Excavated pond construction in Florida, CIR939, Agricultural and Biological Engineering Dept., Florida Cooperative Extension Service, Institute of Food and Agricultural Sciences, Univ. of Florida, Gainesville, FL.

Inci, G. (2008). "3D effects on flood protection levees Plane strain versus axisymmetric modelling." Proc., 12th Int. Conf. of Int. Association for Computer Methods and Advances in Geomechanics (IACMAG), Curran Associates, Red Hook, NY, 3820-3826.

Jonkman, S. N., Kok, M., and Vrijling, J. K. (2008). "Flood risk assessment in Netherlands: A case study for dike ring south Holland." Risk Anal., 28(5), 1357-1373.

Kreyszig, E. (2010). Advanced engineering mathematics, 10th Ed., Wiley, New York.

MATLAB 7.12 [Computer software]. Natick, MA, MathWorks.

McCook, D. (2007). "A discussion of uplift computations for embankments and levees." J. Dam Saf., 5(1), 30-39.

Meehan, C. L., and Benjasupattananan, S. (2012). "An analytical approach for levee underseepage analysis." J. Hydrol. (Amst.), 470-471, 201-211.

Ormann, L., Zardari, M.A., Mattsson, H., Bjelkevik, A., and Knutsson, S. (2011). "Numerical analysis of curved embankment of an upstream tailing dam." Electron. J. Geotech. Eng., 16(Bundle I), 931-944.

Pula, W., and Bauer, J. (2007). "Application of the response surface method." Probabilistic methods in geotechnical engineering, No.491, D. V. Griffiths and Fenton, eds., CISM International Centre for Mechanical Sciences, Springer, New York, 147-168.

Strack, O. (1989). Groundwater mechanics, Prentice Hall, Englewood Cliffs, NJ.

Tracy, F. T. (1973). "A plane and axisymmetric finite element program for steady-state and transient seepage problems." Miscellaneous Paper K-73-4, U.S. Army Engineer Waterways Experiment Station, Vicksburg, MS.

Trimbath, K. (2006). "Levees: Ring levee would protect San Joaquin Delta island community." Civ. Eng., 76(11), 28-29.

Turnbull, W. J., and Mansur, C. I. (1961). "Underseepage and its control, a symposium." Transactions of the American Society of Civil Engineers, ASCE, Reston, VA, 1427-1568, Paper No. 3247.

U.S. Army COE (USACE). (1956a). "U.S. Army Corps of Engineers waterways experiment station, investigation of underseepage and its control, lower Mississippi river levees." Technical memorandum 3-424, Vicksburg, MS.

U.S. Army COE (USACE). (1956b). "U.S. Army Corps of Engineers waterways experiment station, investigation of underseepage and its control, Mississippi river levees, St. Louis district, Alton to Gale, IL." Technical memorandum 3-430, Vicksburg, MS.

U.S. Army COE (USACE). (2000). "Design and construction of levees." Engineering manual 1110-2-1913, Washington, DC.

U.S. Army COE (USACE). (2005). "Design guidance for levees." Engineering technical letter 1110-2-555, Washington, DC. 
Van, M.A., Koelewijn, A.R., and Barends, F.B. (2005). "Uplift phenomenon: Model, validation and design." Int. J. Geomech., 10.1061/(ASCE)1532-3641(2005)5:2(98), 98-106.

Van Zyl, D., and Harr, M. E. (1981). "Seepage erosion analyses of structures." Proc., 10th Int. Conf. on Soil Mechanics and Foundation Engineering, Vol. 1, Balkema, Rotterdam, Netherlands, 503-509.
Verruijt, A. (1970). Theory of groundwater flow, Macmillan, London.

Watson, G. N. (1922). A treatise on the theory of Bessel functions, Macmillan, New York.

Weir, G. J. (1987). "Steady infiltration from small shallow circular ponds." Water Resour. Res., 23(4), 733-736.

Wooding, R. A. (1968). "Steady infiltration from a shallow circular pond." Water Resour. Res., 4(6), 1259-1273. 

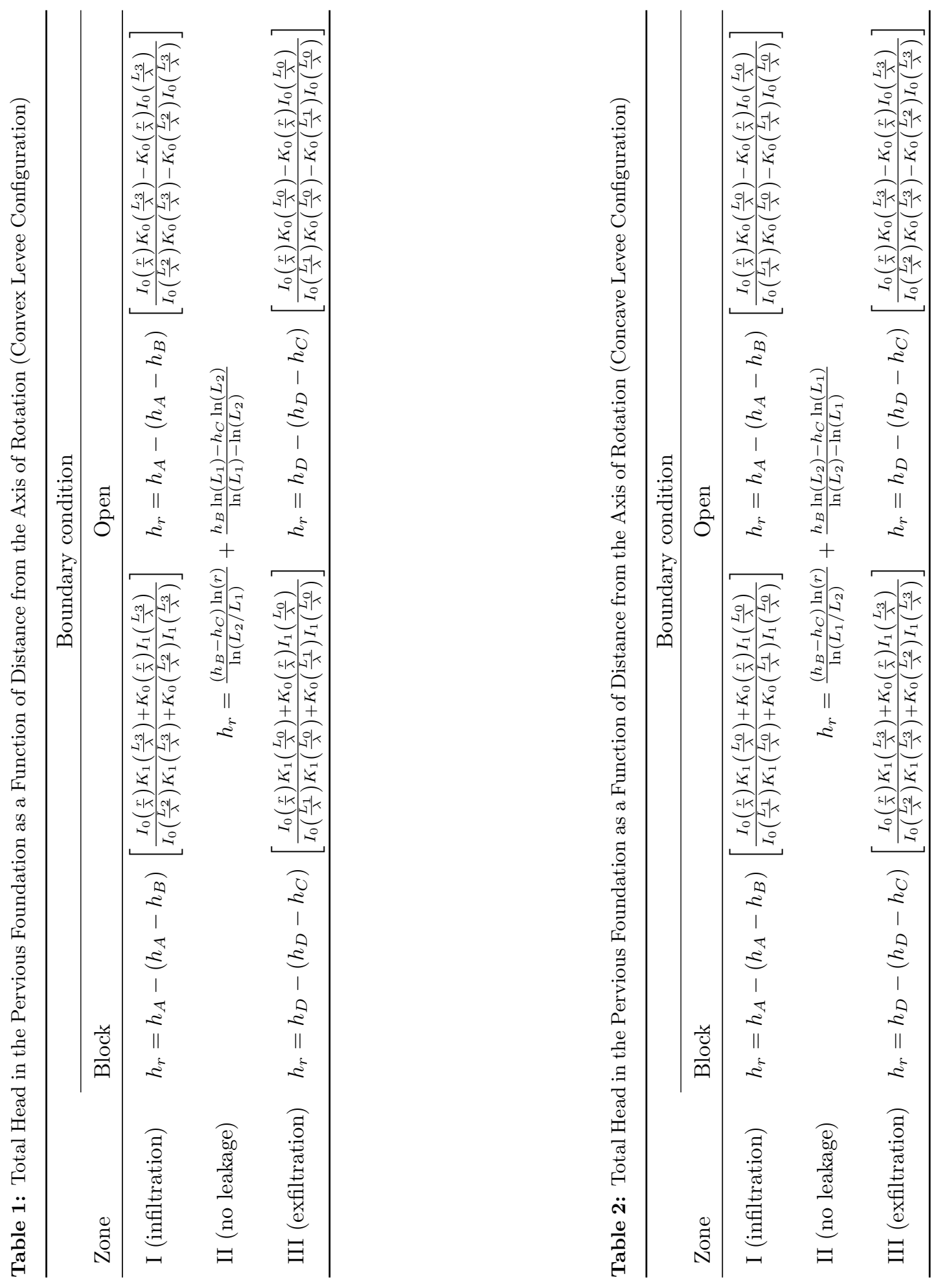

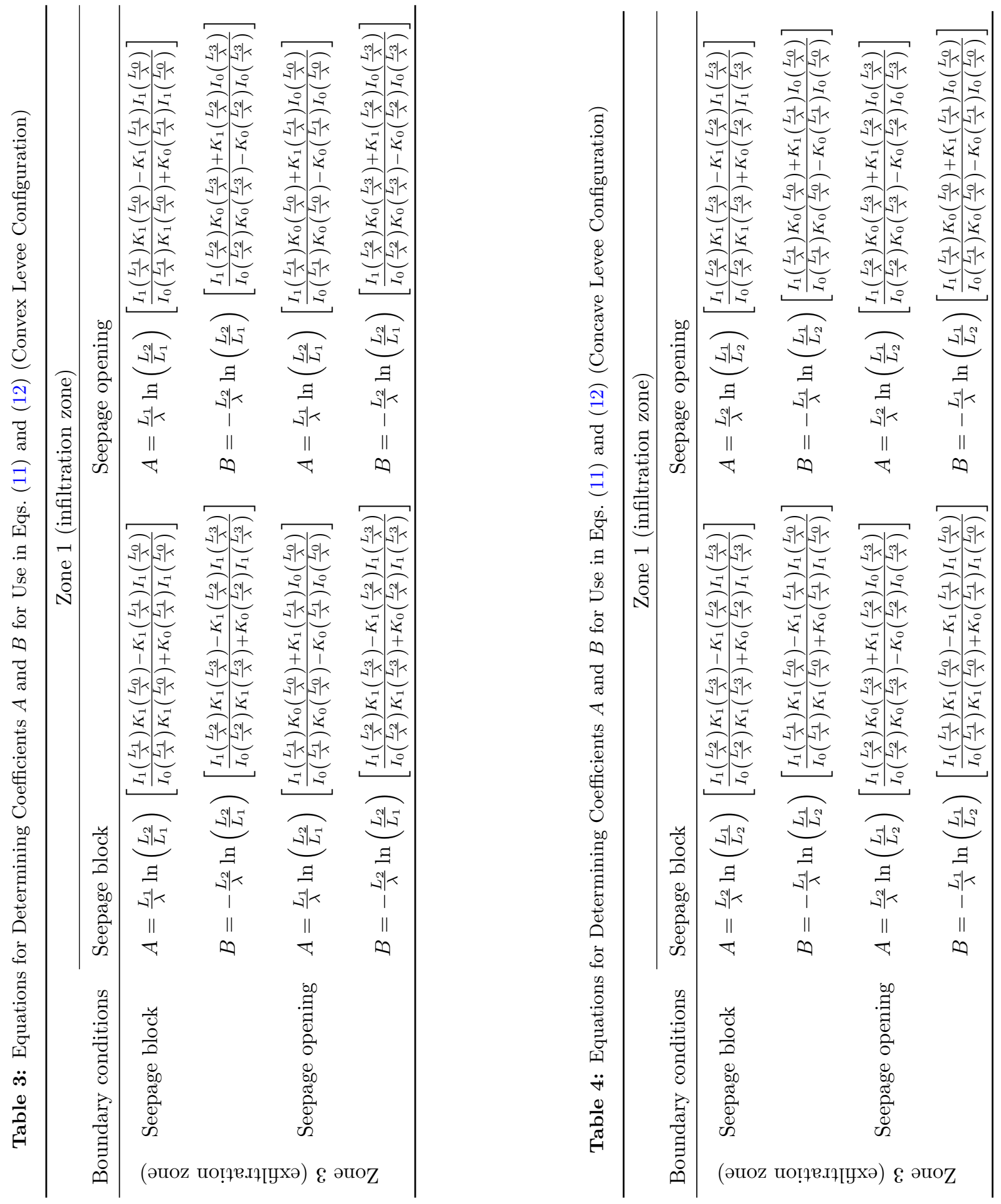